\section{Forest engineering conference}

Held in connection with the 64th annual meeting of the American Society of Agricultural Engineering, and co-sponsored by the Western Forestry and Conservation Association, the Forest Engineering Conference (Pullman, Washington, June 27-30, 1971) featured about 20 technical papers dealing particularly with recent developments in the mechanization of silviculture. Keynote speaker was W. Ross Grinnell Ontario Department of Lands and Forests, who emphasized that future forestry programs will have to relate to total land-use plans. Foresters must fully appreciate socioeconomic needs, and build goals that are predicated on a balanced total system landuse plan, with due consideration given to the maintenance of the environment. Grinnell noted that adjustments in harvesting systems can improve the aesthetics while reduced regeneration costs can be achieved with careful planning.

\section{Seed collection systems}

In mechanized cone harvesting the most successful machines have proven to be inertia shakers, of which several are on the market. Various seed collection systems, including catching frames built of steel tubing with polypropylene cloth, a mechanized catching canvas with a belt-type harvester, and a rotary pickup collector (a self-propelled sweeper) were described. However, more work still needs to be done to develop suitable equipment.

\section{Nursery stock production}

There are problems of precision row seeding in the bare-root nursery. Precision seeding is desirable in that it should maximize the yield of marketable seedling per unit of nursery bed. Recent tests with available seeding machines indicated that none had accomplished precision sowing over the range of sowing rates required.

Modification of the nursery climate can improve seedling root growth capacity. Root growth capacity of ponderosa pine is largely controlled through cumulative exposure to low air temperatures; lowering of night air temperatures could be beneficial in producing ponderosa pine bare-root stock in California.

\section{Site preparation for regeneration}

No paper dealt specifically with mechanized site preparation, probably the most commonlyemployed technique in North America.

There is need for complete utilization to reduce slash burning and to develop harvesting methods that will not adversely affect the environment; balloon, helicopter and skyline logging are possibilities. Controlled release of herbicides by combining them with a polymer substitute of substrate bark and lignin was described. The herbicide is released slowly and the technique could minimize pollution possibilities, and lower potential toxicity to humans and wildlife.

Two papers dealt with prescribed burning.

\section{Containerized seedling systems}

Speakers generally reported very recent developments, most of which were still in the research stage. No papers dealt with the extensive research and operational programs being carried out in B.C., Alberta and Ontario.

Papers described 1/ work underway in preparing and testing extruded peat cylinders, commonly known as sausages. Peat is extruded at controllable levels of compaction into a thin-walled plastic casing which is split during the planting operation. 2/ Preliminary work with an extruded soil media container preformed into $1 / 2$-or 1 -inch squares, 4 inches in length. 3/ Work in producing coniferous seelings in soilless wood pulp containers. 4/ Preliminary experiences in aerial planting of conifers grown in modified plastic bullets and also seedlings frozen in soil-moss with plastic fins attached. 5/ The progress and potential of containerized seedlings in southern United States. Tubelings could not be justified for the area on the basis of cost of growing seedlings, but containerized seedlings offer advantages in scheduling of planting, labor utilization, automation, and seedling survival.

The need to develop mechanized methods for the growing and planting of containerized stock was emphasized.

\section{Forest tending}

In mechanical thinning of young stands by row thinning using various types of machinery (including blades, roller-choppers, and crushers as a first operation in a stand rehabilitation program) problems noted were the resultant fire hazard, aesthetic limitations, and snow breakage and wind damage in leave strips. Chemical thinning techniques both in pre-commercial and commercial operations were emphasized. In the latter, referred to as "preharvest drying", implications with respect to fungal damage, transportation, drying and the environment were noted. In the concept of an automated system for thining in southern pine plantations, trees are felled by a self-propelled thinner which is guided by tree locations and spacings within the stand. A discussion of current practices and problems in forest fertilization and the benefits and limitations of operational irrigation completed the papers presented.

Based on notes by J. H. Cayford 